\title{
Optimization temperature in the room using air conditioner with finite element methods
}

\author{
Tulus Tulus*, Lamtiur Simbolon, Sawaluddin Sawaluddin, and T.J. Marpaung \\ Universitas Sumatera Utara, Department of Mathematics, Padang Bulan 20155 Medan, Indonesia
}

\begin{abstract}
Room temperature is one of the problems in everyday life that is often discussed. One of the tools in regulating the temperature is Air Conditioner (AC). As is known, that the AC work process in cooling the room is the process of heat transfer. This study aims to find out how the $\mathrm{AC}$ works in regulating the temperature in a room. In the process, this research is accomplished by implementing finite element method on the energy transfer equation. Where the energy transfer equation is the partial differential used for heat transfer. In the finite element method, the flow field is broken down into a set of small fluid elements (discrete domains). In the solution, use it in three-dimensional space, then select the linear interpolation function for the $3 \mathrm{D}$ element, and derive the matrix and vector elements by the Galerkin method to obtain global equations. Results from computer-assisted studies show the temperature distribution in the room of COMSOL Multiphysic 5.0. Simulation results with COMSOL show that there is a correlation between AC location and solar radiation indoors against indoor temperature.
\end{abstract}

\section{Introduction}

Air Conditioner (AC) is a device that serves to control the air temperature in certain spaces. Where AC changes the temperature of hot air into cold air in the room becomes more comfortable. In this study, temperature changes in a space by $\mathrm{AC}$ can be simulated in the COMSOL Multiphysic 5.2 program. Where COMSOL is a simulation software with finite element method, which can basically simulate various physics and engineering applications, such as simulation of heat transfer through complex structures and others. A major advantage in combining computer simulations and analysis of key principles is that users can try different approaches to the same problem solution that is required to get a solution that is close to its true optimum value.

The common differential equations for heat transfer are as follows [1]

$$
\nabla \cdot(-k \nabla T)+\rho C_{p} \cdot u \cdot \nabla T=q
$$

where $k$ is the thermal conductivity $(\mathrm{W} / \mathrm{mK}), T$ is the reaction temperature of flow $(\mathrm{K}), \rho$ is the density $\left(\mathrm{kg} / \mathrm{m}^{3}\right), C_{p}$ is the heat capacity at constant pressure $(\mathrm{J} / \mathrm{kgK}), u$ is the speed field $(\mathrm{m} / \mathrm{s}), q$ is the volumetric rate of thermal energy generation $\left(W / \mathrm{m}^{3}\right)$.

\section{Basic Theory}

\subsection{Air Conditioner (AC)}

Knowledge of air cooling function has evolved since roman times. Food stored in a cold place will last longer than in hot spots. In cold air, the movement of bacteria is slower, resulting in longer decay process. Therefore, people in those days kept food in the basement or in the well. In the winter people in the northern region cut ice from frozen lakes. They store them in sawdust or refrigeration buildings and sell them to residents in the south in the summer.

At the end of the 18th century, winter in the northern regions experienced an increase in temperature. It was during these days that people began to develop cooling machines to make ice. Then came the tool known as the "ice box". This tool is used to preserve food.

Refrigerators with freezers (now we call them ice box). Since then, the cooling system has grown rapidly. People not only use cooling systems to preserve food, but also for air conditioning.

To optimize ac performance as an air conditioner there are several ways that can be done among others:

1. determine the performance coefficients, or commonly known as COP (Coefficient of Performance).

2. testing the Energy Efficiency Ratio (EER).

3 . choose the right size of air conditioner.

4. choose better freon quality.

5. perform ac treatment periodically.

\footnotetext{
* Corresponding author: tulus@usu.ac.id
} 


\subsection{Heat Transfer}

Heat transfer is the science of forecasting the transfer of energy that occurs due to temperature differences between objects or materials [2]. The science of heat transfer not only tries to explain how the heat energy travels from one object to another, but also to predict the rate of displacement occurring under certain conditions. Heat transfer consists of three forms, namely:

\subsubsection{Conduction}

If there is a temperature gradient in the body (temperature gradient), then experience the transfer of energy from the high temperature to the low temperature. We say that energy moves by conduction and that the rate of heat transfer is proportional to the normal temperature gradient.

$$
\frac{q}{A} \sim \frac{\partial T}{\partial x}
$$

where :

$q \quad$ : rate of heat transfer

$\frac{\partial T}{\partial x} \quad$ : temperature gradient toward heat transfer

$k$ : conductivity or thermal conductivity of objects

A : wide of normal area (perpendicular) to the direction of heat flow $m^{2}$ or $f t^{2}$

\subsubsection{Convection}

If a hot plate is left in the air around it without any external source of movement, it will move as a result of the density gradient near the plate. This event is called natural convection or free convection to distinguish it from forced convection which occurs when the air is exhaled over the plate with fan. The boiling and condensation phenomena are also included in the group of convection heat transfer problems.

$$
\frac{q}{A}=h \nabla T
$$

where:

$q \quad$ : convective heat transfer rate (W)

$A$ : wide of normal area (perpendicular) to the direction of heat flow $\left(\mathrm{m}^{2}\right.$ or $\left.f t^{2}\right)$.

$\nabla T:$ the temperature difference between the surface and the fluid $\left({ }^{0} \mathrm{~K}\right.$ or ${ }^{0} \mathrm{~F}$ )

$h$ : convective heat transfer coefficient $W / m^{2} K$

\subsubsection{Radiation}

Unlike conduction and convection mechanisms, where energy transfer occurs through intermediate materials, the heat can also move through empty regions. The mechanism here is electromagnetic radiation or radiation.

$$
q_{\{\text {radiance }\}}=\sigma A T^{4}
$$

where $\sigma$ is the constant of proportionality (StefanBoltzmann constant) with value $5,669 \times 10^{-8} \mathrm{~W} /$ $m^{2} \cdot K^{4}$.

\subsection{Optimization}

The optimization module can be used throughout the COMSOL product that provides a common solution to calculate the optimal solution for engineering problems [3]. Any input model, whether geometric dimension, shape part, material properties, or material distribution, can be required as a variable control, and any output model bias becomes a function of purpose. In many cases one or more simulations are not enough to provide sufficient understanding of the system. The problem that resolution relies on the more systematic exploration process provided by the Optimization Module can be broadly divided into two classes is:

1. Design issues with one purpose.

2. Inverse Problems, and estimation of certain parameters in Partial Differential Equations.

\subsection{Laminar and Turbulent Flows}

Viscous flow can be divided into two types namely laminar and turbulent flow. In the laminar stream, the liquid particles move regularly following the parallel trajectory. Laminar flow occurs when the velocity is small and / or large viscosity. $n$ the turbulent flow the motion of the particles of irregular liquids. This flow occurs when large velocity and small liquid density.

\subsection{Finite Element Metod}

Finite Element Method is a numerical method used to solve engineering problems and mathematical problems of a physical phenomenon [4].

Steps in the finite element method are as follows [5]

1. Formulate governing equations and boundary conditions

2. Divide the area of analysis into elements (discretization)

3. Selecting interpolation function

4. Determining element properties

5. Assemble / merge global equations

6. Solutions for global equations

7. Verify the solution.

\subsection{COMSOL Multyphysic $\mathbf{5 . 2}$}

COMSOL Multiphysics 5.2 is a significant expansion of software applications, features and functions. COMSOL Multiphysics has several troubleshooting benefits, using COMSOL can help understand the problem and can test various geometric and physical characteristics of the model. Models are presented in the context of the physical world (applied physics) and explored in light of the techniques of analysis of key principles. As with any other method of problem solution, the information contained in the solution of this computer simulation is good as the material coefficients and the basic assumptions used in model building. 


\section{Methods}

1. Preliminary studies

In this study, first seek and collect sources such as books, journals or previous studies that support research and are written down in basic theory. The sources used preferably relate to partial differential equations, heat transfer, and simulations using the Multiphysic COMSOL program.

2. Second stages are analysis with COMSOL Multiphysics. The steps in the simulation with COMSOL Multiphysic program are

- Differential Equations for Energy Transfer.

- Turbulent flow of indoor flow.

- Boundary Condition.

- Domain Settings section.

- Meshing.

- Problem solving.

3. Third stages are make a conclusion of the model obtained with the program COMSOL Multiphysic. And will be seen how the optimization of cooling in a room using AC.

\section{Discussion}

\subsection{Simulation with COMSOL Multiphysics $\mathbf{5 . 2}$}

\subsubsection{Shape Room Geometry with COMSOL Multiphysics}

In this model, conditioned a $4 \times 3 \times 4$ beam-shaped room in meters, in the room there are two AC which are inlets of rectangular geometry measuring $0.05 \times 0.6$ in meters, and square outlets measuring $0.5 \times 0.5$ in meters and there is a human being in the room beam-shaped. The indoor temperature was $309 \mathrm{~K}$, the human temperature in the room was $307 \mathrm{~K}$, and the initial AC temperature was 293 $\mathrm{K}$. Here is a room model created with COMSOL Muliphysics 5.2.

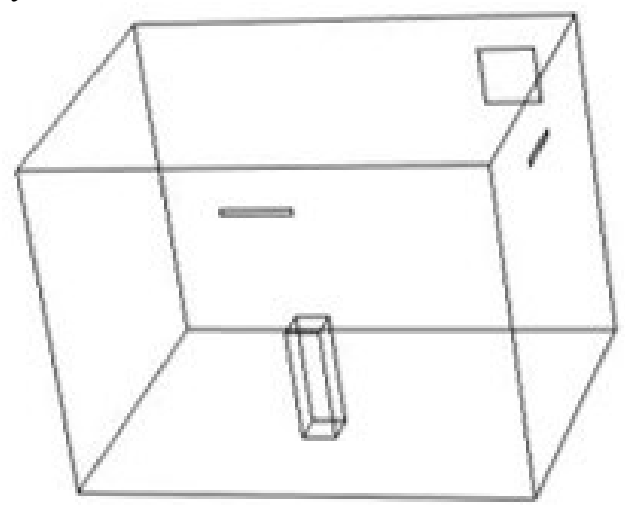

Fig. 1. Model room on COMSOL Multiphysics 5.2.

\subsubsection{AC Optimization Parameters and Properties with COMSOL Multiphysics}

From the model to be studied, needed some data in making the simulation in the room. The data to be used is the parameters and information that will be used and inserted into the analysis data in the program. The data obtained are as follows.

Table 1. AC Optimization Parameters.

\begin{tabular}{|l|l|l|l|}
\hline Nama & Expression & Value & Description \\
\hline $\mathrm{T}_{\mathrm{h}}$ & $36[\mathrm{degC}]$ & $309 ; 15 \mathrm{~K}$ & $\begin{array}{l}\text { Human } \\
\text { Temperature }\end{array}$ \\
\hline $\mathrm{T}_{\text {amb }}$ & $34[\mathrm{degC}]$ & $307 ; 15 \mathrm{~K}$ & $\begin{array}{l}\text { Ambient } \\
\text { Temperature }\end{array}$ \\
\hline $\mathrm{T}_{\text {source }}$ & $17[\mathrm{degC}]$ & $290 ; 15 \mathrm{~K}$ & $\begin{array}{l}\text { Air Conditioner } \\
\text { Temperature }\end{array}$ \\
\hline $\mathrm{T}_{\mathrm{av}}$ & $\begin{array}{l}\left(\mathrm{T}_{\text {amb }}+\mathrm{T}_{\mathrm{h}}+\right. \\
\mathrm{T}_{\text {source }} / 3\end{array}$ & $302 ; 15 \mathrm{~K}$ & $\begin{array}{l}\text { Average } \\
\text { Temperature }\end{array}$ \\
\hline $\mathrm{U}_{\text {in }}$ & $0 ; 3[\mathrm{~m} / \mathrm{s}]$ & $0 ; 3 \mathrm{~m} / \mathrm{s}$ & air velocity \\
\hline $\mathrm{W}_{\mathrm{R}}$ & $4[\mathrm{~m}]$ & $4 \mathrm{~m}$ & Width Room \\
\hline $\mathrm{D}_{\mathrm{R}}$ & $3[\mathrm{~m}]$ & $3 \mathrm{~m}$ & Depth Room \\
\hline $\mathrm{H}_{\mathrm{R}}$ & $4[\mathrm{~m}]$ & $4 \mathrm{~m}$ & Height Room \\
\hline $\mathrm{W}_{\mathrm{AC}}$ & $60[\mathrm{~cm}]$ & $0,6 \mathrm{~m}$ & $\begin{array}{l}\text { Air Conditioner } \\
\text { Width }\end{array}$ \\
\hline $\mathrm{L}_{\mathrm{AC}}$ & $5[\mathrm{~cm}]$ & $0,05 \mathrm{~m}$ & $\begin{array}{l}\text { Air Conditioner } \\
\text { Length }\end{array}$ \\
\hline $\mathrm{S}_{\mathrm{ot}}$ & $50[\mathrm{~cm}]$ & $0.5 \mathrm{~m}$ & Side Outlet \\
\hline
\end{tabular}

\subsubsection{AC Optimization Material with COMSOL Multiphysics}

Table 2. AC Optimization Properties

\begin{tabular}{|c|c|}
\hline Properties & Value \\
\hline Density & $1,127 \mathrm{Kg} / \mathrm{m}^{3}$ \\
\hline Dynamic Viscosity & $1,983 . \mathrm{e}^{-5 \mathrm{~Pa} . \mathrm{s}}$ \\
\hline Heat Capacity Constant Pressure & $1,005 \mathrm{~J}(\mathrm{~kg} . \mathrm{K})$ \\
\hline Thermal Conductivity & $0,0271 \mathrm{Wm} . \mathrm{K}$ \\
\hline
\end{tabular}

\subsubsection{Mesh AC Optimization with COMSOL Multiphysics}

Table 3. Statistics Mesh for AC room.

\begin{tabular}{|c|c|}
\hline Properties & Value \\
\hline Maximum Element Size & 0,4 \\
\hline Minimum Element Size & 0,07 \\
\hline Maximum average Element & 1,5 \\
\hline Arch factor & 0,6 \\
\hline Resolution of narrow section & 0,5 \\
\hline
\end{tabular}

Here's a picture mesh room in AC optimization

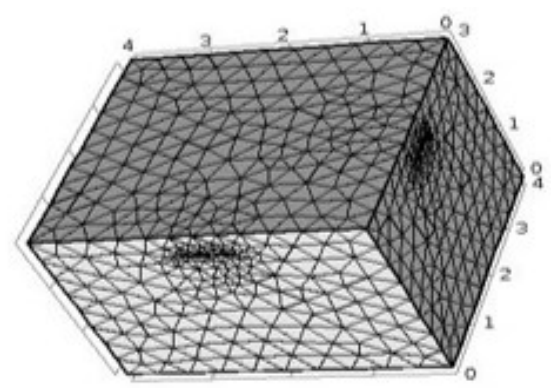

Fig.2. Mesh in Room. 


\subsubsection{Temperature Distribution}

(a) Temperature Relation Room with inlet temperature (AC temperature).

The room is $4 \times 4$ in size, there are 2 air conditioners in it where its inlet temperature $16^{\circ} \mathrm{C}, 17^{\circ} \mathrm{C}, 18^{\circ} \mathrm{C}, 20^{\circ} \mathrm{C}$.

i. Inlet Temperature for $16^{\circ} \mathrm{C}$

Slice: Temperature $(\operatorname{deg} c)$

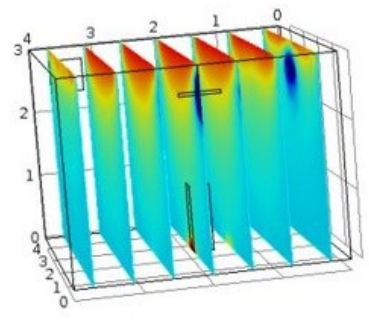

Fig.3. Temperature Distribution Room with inlet temperature $16^{\circ} \mathrm{C}$.

ii. Inlet Temperature for $17^{\circ} \mathrm{C}$

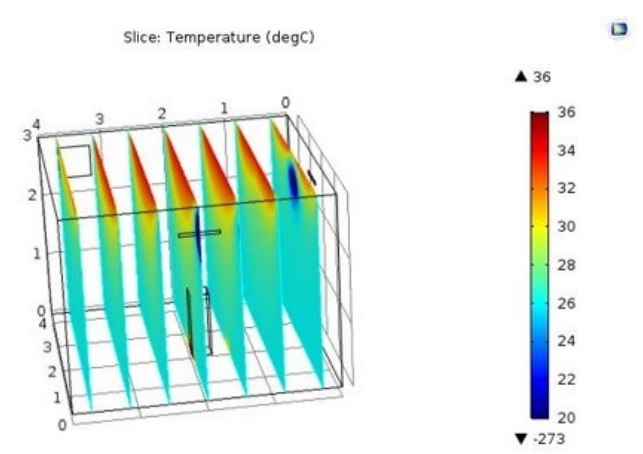

Fig.4. Temperature Distribution Room with inlet temperature $17^{\circ} \mathrm{C}$.

iii. Inlet Temperature for $18^{\circ} \mathrm{C}$

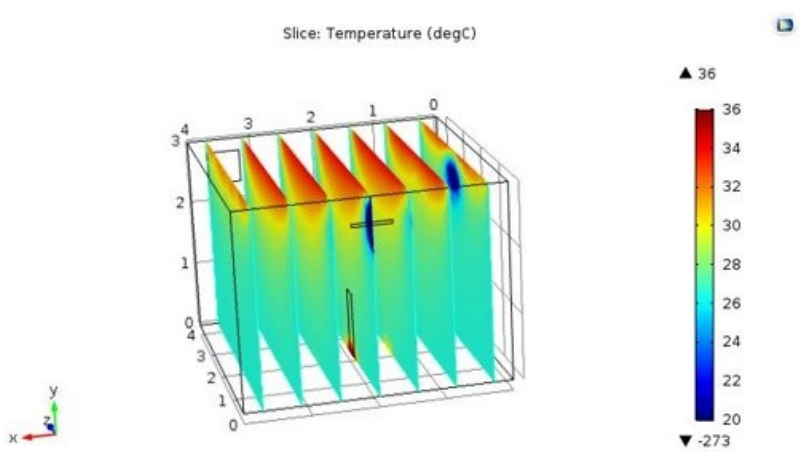

Fig.5. Temperature Distribution Room with inlet temperature $18^{\circ} \mathrm{C}$. iv. Inlet Temperature for $20^{\circ} \mathrm{C}$

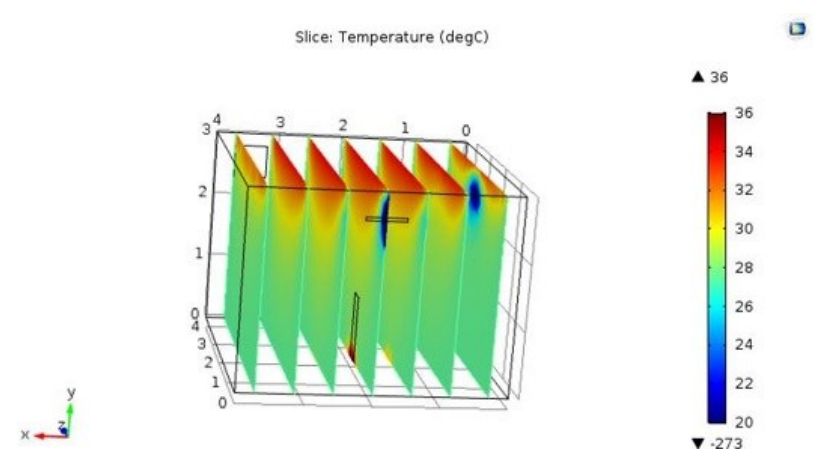

Fig.6. Temperature Distribution Room with inlet temperature $20^{\circ} \mathrm{C}$.

(b) Relationship of Room Temperature with Longest Wall The size of the room is conditioned differently, there is one air conditioner in it where the temperature $\mathrm{AC}$ is $18^{\circ} \mathrm{C}$

i. Room Sized $4 \times 4 \mathrm{~m}^{2}$

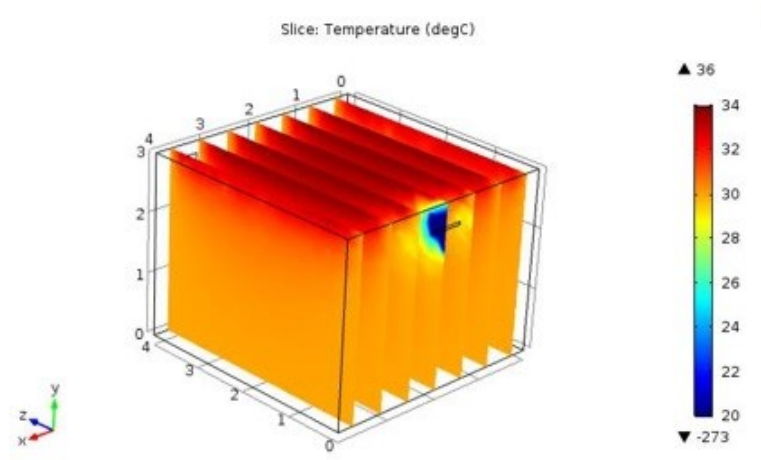

Fig.7. Room Sized $4 \times 4 \mathrm{~m}^{2}$.

ii. Room Sized $7 \times 7 \mathrm{~m}^{2}$

Slice: Temperature (degc)

$\square$

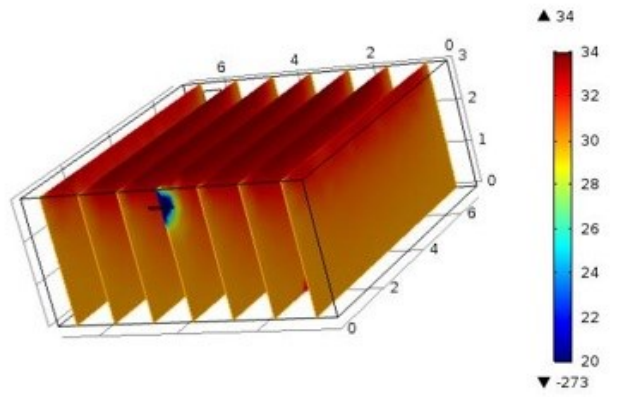

Fig.8. Room Sized $7 \times 7 \mathrm{~m}^{2}$. 
iii. Room Sized 10x10 $\mathrm{m}^{2}$

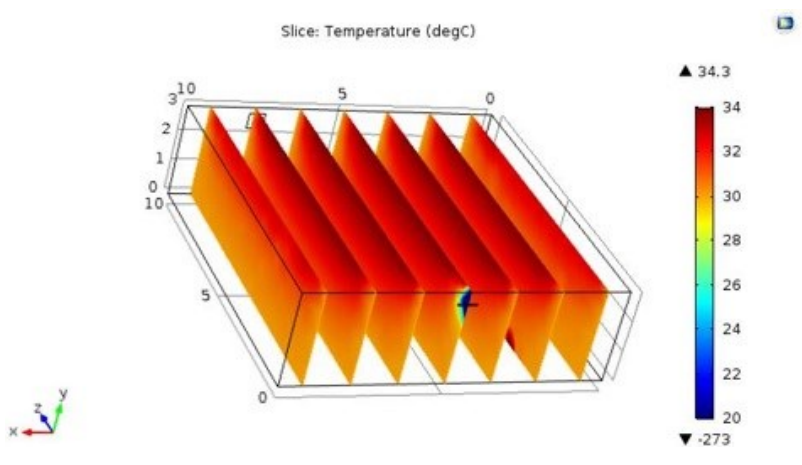

Fig.9. Room Sized 10x10 m².

(c) Relationship of Room Temperature with AC Location Room Sized $5 \times 6 \mathrm{~m}^{2}$, there is one air conditioner inside, which is located in front and beside, where temperature $\mathrm{AC}$ is $18^{\circ} \mathrm{C}$

i. Location of $\mathrm{AC}$ in front of the room

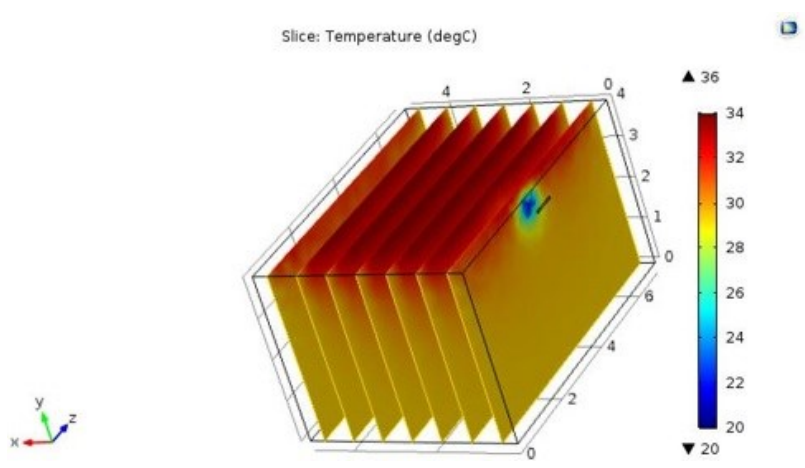

Fig.10. Temperature distribution from front position.

ii. Location of $\mathrm{AC}$ beside Room

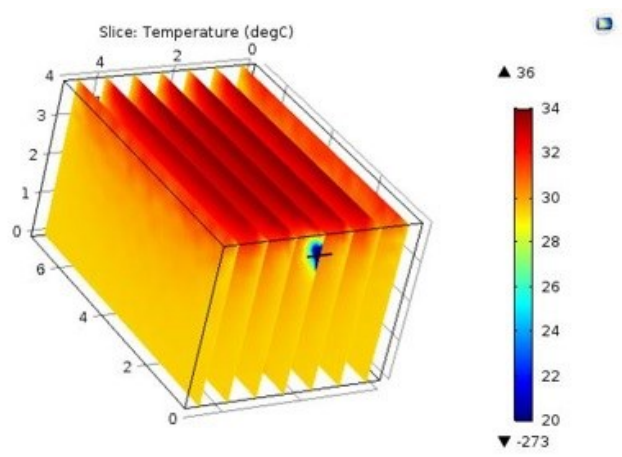

Fig.11. Temperature distribution from beside position.

\section{Conclusion}

According to the study, a comfortable room for about $20^{\circ}$ $25^{\circ}$. From the simulation results with COMSOL show that the room with two air conditioners inside and the inlet temperature $16^{\circ} \mathrm{C}$ is the most comfortable room temperature with its temperature ranging from $24^{0}-26^{\circ} \mathrm{C}$.
There is a relationship between the walls of the longest room with the room temperature and if the air conditioner is placed on the shortest wall the room temperature will be more optimal. This research is expected to be a reference in determining the optimal position of an $\mathrm{AC}$ to obtain the desired optimum temperature in a room. And also as one example of study in the use of finite element method in many other cases.

\section{References}

1. Welty, J.R., Charles, E.W., Robert, E.W, Gregory, L.R. (2004). Dasar-Dasar Fenomena Transport. Edisi Keempat. Volume-II Transfer Panas. Erlangga. Jakarta

2. Holman, Jack P. (1997). Perpindahan Kalor. Penerjemah E. Jasjfi. Erlangga. Jakarta.

3. Triatmodjo, Bambang. (1993). Hidraulika II. Beta Offset. Yogyakarta.

4. Rao, S. S. (2011). Fifth edition, The Finite Element Method in Engineering. British Library. USA.

5. Allaire, Paul E. (1985). Basic of the Finite Element Method : Solid Mechanics, Heat Transfer and Fluid Mechanics. Wm. C. Brown. USA. 